\title{
Ligamentum Flavum Cyst of Lumbar Spine: A Case Report and Literature Review
}

\author{
Dong-Ho Seo, Hye-Ran Park, Jae-Sang Oh, Jae-Won Doh \\ Department of Neurosurgery, Soonchunhyang University College of Medicine, Cheonan, Korea
}

Ligamentum flavum cysts have rarely been reported and known to be the uncommon cause of spinal compression and radiculopathy. A 63-year-old man presented right sciatica lasting for 1 month. Lumbar computerized tomography and magnetic resonance imaging demonstrated an extradural cystic mass adjacent to the L5-S1 facet joints. Partial hemilaminectomy and flavectomy at the L5-S1 space were performed, and then the cystic mass was excised. Histopathology confirmed a connective tissue cyst, which is consistent with the ligamentum flavum. Microscopic examination of the cyst wall revealed that it is closely packed collagen fibril. The symptom of patient was improved after surgery. Because of rarity of ligamentum flavum cysts and nonspecific clinical and radiologic findings, the preoperative diagnosis is not easy. The histologic features of ligamentum flavum cysts are distinct from other cystic lesion of lumbar spine. This study presents a case and literature review of ligamentum flavum cyst. We summarize the pathophysiology, occurrence, differential diagnosis of rare ligamentum flavum cyst, especially on lumbar spine.

Key Words: Cyst • Ligamentum flavum $\cdot$ Lumbar vertebrae

\section{INTRODUCTION}

After first report by Moiel et al. in $1967^{19)}$, cysts of the ligamentum flavum have rarely been reported and they are known to be an uncommon cause of spinal compression and radiculopathy ${ }^{22}$. Ligamentum flavum cyst is one of the juxtafacet cysts. Kao et al. ${ }^{15)}$ and Rhoton et al. ${ }^{21)}$ first used the term "juxtafacet cyst" in 1974 to describe synovial and ganglion cysts that are adjacent to the facet joints or arise from or grow into the ligamentum flavum. Some authors classified juxtafacet cysts into three types by location: facet cyst, flavum cyst, and posterior longitudinal ligament (PLL) cyst ${ }^{1)}$. Histologically, juxtafacet cysts are classified into the two types: a synovial cyst with a synovial lining membrane and a ganglion cyst with no synovial lining membrane. In 1995, Chimento et al. ${ }^{9)}$ reported that almost all cysts of the ligamentum flavum and PLL are ganglion cysts. But the pathophysiology of liga-

\footnotetext{
- Received: December 31, 2013 • Revised: February 17, 2014

- Accepted: March 6, 2014

Corresponding Author: Jae-Sang Oh, MD

Department of Neurosurgery, Soonchunhyang University Cheonan Hospital 8 Soonchunhyang 2 Gil, Dongnam-gu, Cheonan 330-721, Korea

Tel: +82-41-570-2180, Fax: +82-41-572-9297

E-mail: metatron1324@hotmail.com

$\otimes$ This is an Open Access article distributed under the terms of the Creative Commons Attribution Non-Commercial License (http://creativecommons.org/ licenses/by-nc/3.0/) which permits unrestricted non-commercial use, distribution, and reproduction in any medium, provided the original work is properly cited.
}

mentum flavum cysts has not yet been fully elucidated.

In current report, the authors present one case of ligamentum flavum cyst on lumbar spine and summarize their pathophysiology, occurrence, differential diagnosis, on the reported articles.

\section{CASE REPORT}

A 63-year-old man presented with right sciatica of 1 month's duration. He also suffered from low back pain and hypoesthesia of the posterior aspect of the right lower extremity. On neurological examination, he had no motor paresis, intermittent claudication or urinary incontinence. We performed computerized tomography (CT) and magnetic resonance imaging (MRI) to evaluate the spinal lesion.

CT imaging of the lumbosacral spine showed some degenerative marginal osteophytes and degenerative facet arthropathy in the lumbar spine. Axial CT on the L5/S1 level showed ruptured disc-like material, but it had an unusual isodensity mass within air density. And CT-myelogram showed an extradural cystic mass, located in the dorsal area of the right inferior facet and the dorsolateral area of the right $\mathrm{S} 1$ root and thecal sac (Fig. 1). MRI revealed a $1.2 \mathrm{~cm}$ sized cystic lesion rather than a disc, compressing the thecal sac and right $\mathrm{S} 1$ nerve root in the right L5-S1 facet joint. The cystic lesion showed isointensity mass on T1 and T2-weighted images. And it seemed to originate from the facet or ligament flavum (Fig. 


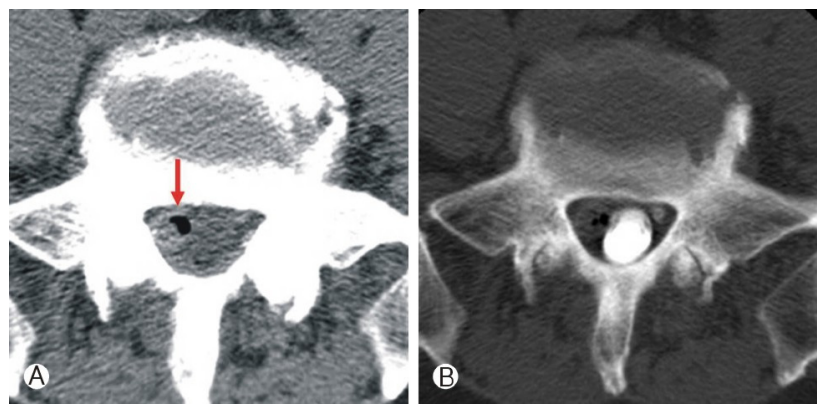

Fig. 1. Lumbar axial computerized tomography (CT) on L5/S1 level showing the ruptured disc-like material, but is unsual isodensity mass within air density (A). CT after myelogram showing the extradural mass, locating ventrolateral area of right S1 root (B).
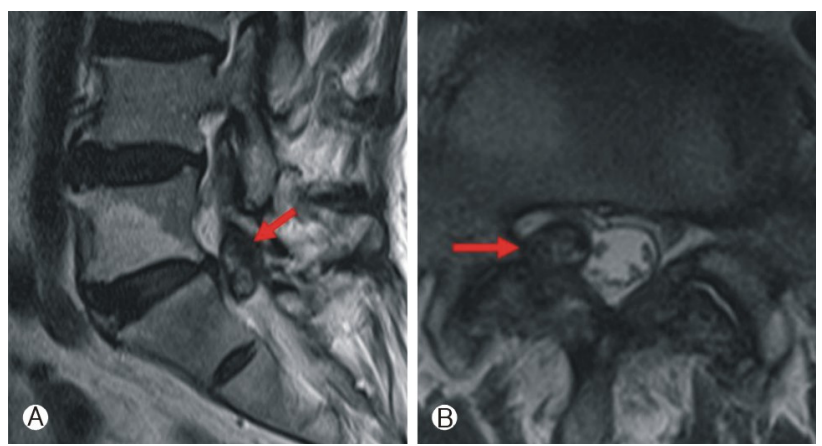

Fig. 2. T2-weighted sagittal magnetic resonance imaging (MRI) showing that the $1.2 \mathrm{~cm}$ sized cystic mass was disconnected the L5-S1 intervertebral disc and seemed to originate from facet or ligament flavum (A). T2-weighted axial MRI demonstrating the isointense mass. In addition, it compressing the thecal sac and right $\mathrm{S} 1$ nerve root $(\mathrm{B})$.

2). Based on these radiologic finding and clinical symptoms, we diagnosed this lesion as a synovial cyst and performed an operation.

The patient was placed under general anesthesia in the prone position. A longitudinal midline incision with exposure of the L5-S1 junction was made. As we carried out partial hemilaminectomy on the right L5 lamina, we found moderate thickening of the capsule of the apophyseal joint and thickened ligamentum flavum. The mass was originated from ligament flavum and contained yellow cystic fluid. The mass compressed the thecal sac and tightly adherent to dura. While the cyst and the ligament were adherent to the dura, there was no communication with the subarachnoid space or connection with the apophyseal joint (Fig. 3). The right S1 nerve root was compressed and pushed laterally by the cyst, and after removal of cyst, nerve root was completely released. There were tight adhesions to dura around the cyst, so dural tearing and CSF leakage occurred during the mass removal. We sealed the dural tear site using a Tachocomb, and per-

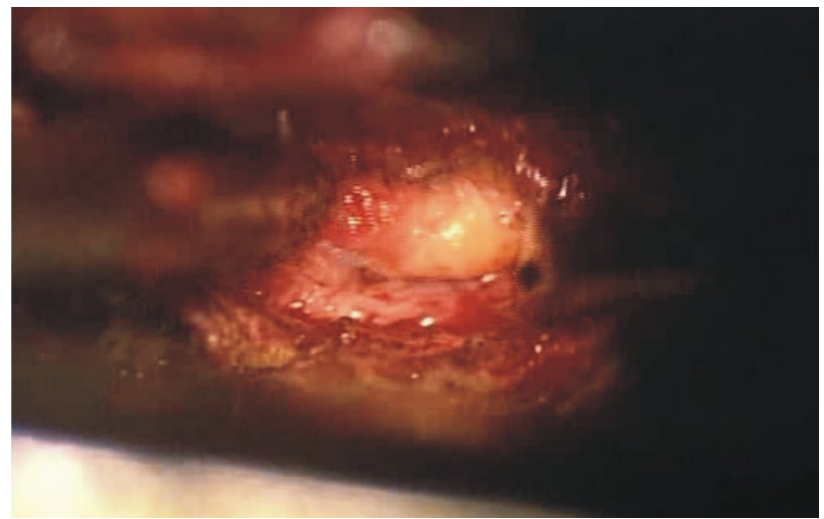

Fig. 3. Intraoperative finding. The mass was originated from ligament flavum and contained cystic fluid. The mass was compressing the thecal sac and tightly adherent to dura.

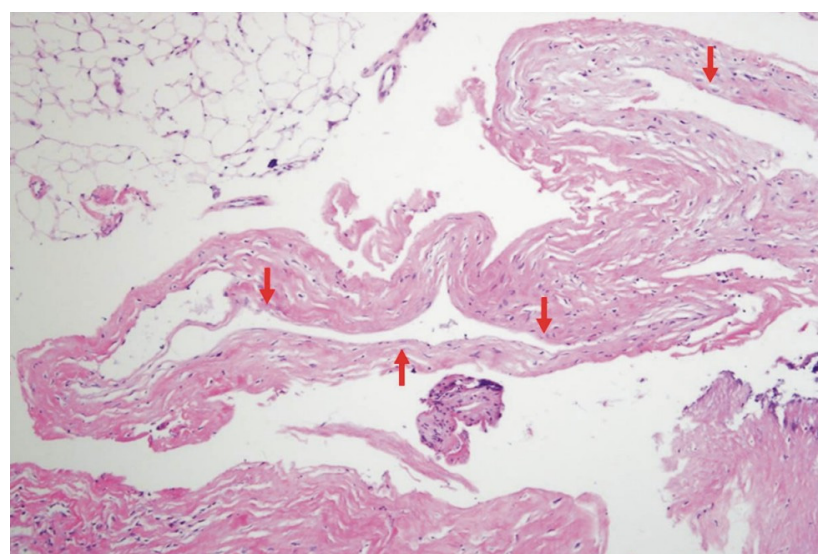

Fig. 4. Photomicrograph of the surgical specimen showing cyst formation. The cyst wall (arrows) consists of fibrotic connective tissue without synovial lining $(\times 200, H \& E)$

formed lumbar drainage. In addition, we could not find a protruding disc or any other mass compressing the root.

Histopathology confirmed a connective tissue cyst consistent with a cyst of the ligamentum flavum. Histopathologic microscopic examination of the cyst wall revealed that this was closely packed collagen fibrils without a synovial lining (Fig. 4). There was no nerve tissue in the wall and it was not covered by epithelium. The patient had relief from the sciatica and hypoesthesia after surgery completely. The lumbar drain was removed after one week and the patient was discharged free of pain.

\section{DISCUSSION}

Anatomically, the ligamentum flavum is attached above and below to the lamina and laterally to the capsule of the articular facets. The ligament turns dorsally in the intervertebral fora- 
Table 1. Reported 66 cases of ligament flavum cysts occurring in the lumbar spine

\begin{tabular}{lrll}
\hline \hline \multicolumn{1}{c}{ Literature } & $\begin{array}{c}\text { No. of } \\
\text { cases }\end{array}$ & Level \& cases \\
\hline Haase (1972) & 1 & L4-5 \\
Abdullah et al. (1984) & 4 & L4-5 (2), L5-S1 (2) \\
Vernet et al. (1991) & 5 & L3-4 (1), L4-5 (3), L5-S1 (1) \\
Baker \& Hanson (1994) & 1 & L5-S1 \\
Bloch et al. (1997) & 6 & L3-4 (2), L4-5 (2), L5-S1 (2) \\
Mahallati et al. (1999) & 1 & L3-4 \\
Barlocher \& Seiler (2000) & 1 & L5-S1 \\
Terada et al. (2001) & 1 & L4-5 \\
Cakir et al. (2004) & 1 & L3-4 \\
Wildi et al. (2004) & 33 & L3-4 (4), L4-5 (25), L5-S1 (4) \\
DiMario et al. (2005) & 4 & L3-4 (2), L5-S1 (2) \\
Asamoto et al. (2005) & 1 & L5-S1 \\
Gazzeri et al. (2007) & 1 & L3-4 \\
Ayberk et al. (2008) & 2 & L2-3 (1), L4-5 (1) \\
Taha et al. (2010) & 1 & L3-4 \\
Wu et al. (201 1) & 1 & L4-5 \\
Joung et al. (2007) & 1 & L4-5 \\
Doh et al. (2013) & 1 & L5-S1 \\
\hline & &
\end{tabular}

men and is fused with the capsule on the lateral surface of the superior articular process in the lumbar spine.

The pathogenesis of ligamentum flavum cysts is not yet fully elucidated, but it has proposed that continuous stress to the ligamentum flavum due to minor chronic trauma such as in spondylolisthesis and degenerative disc disease may predispose a patient to developing this cyst ${ }^{8}$.

Incidence of intraspinal ligamentum flavum cysts is rare and they occur frequently in the lower lumbar region ${ }^{24)}$. Ligamentum flavum cysts in the lumbar spine occur commonly at L4-5 level because this level is the most mobile segment. In the cervical spine, only a few cases have been reported. With article searching about ligamentum flavum cysts, we found the 66 cases of ligament flavum cysts occurring in the lumbar spine. The frequency at lumbar spine of ligamentum flavum cyst was as follows: L4-5 (56\%), L5-S1 (23\%), L3-4 (20\%), L2-3 (1\%) level (Table 1).

There are no specific clinical symptoms for ligamentum flavum cyst. Symptomatic ligamentum flavum cysts usually present with radiculopathy and can mimic symptoms of intervertebral disc herniation ${ }^{11)}$. They can be found incidentally ${ }^{14}$. The clinical symptoms of ligamentum flavum cysts are as follows: $97 \%$ of patients complained of radicular pain, $55 \%$ sensory changes, 39\% motor deficit, 33\% positive Lasèque sign, and $18 \%$ abnormal reflexes. Our patient had low back pain and severe radicular pain, and no motor deficit.

In the past, hypertrophy of the ligamentum flavum was considered as a cause of lumbar nerve root compression in pathologic conditions like spondylosis. With increasing understanding of degenerative diseases of the spine, a new concept of the ligamentum flavum as a cause of pathologic conditions has been established. Besides common degenerative changes in connective tissues like hyaline or mucoid changes, more extensive degenerative changes like necrosis, fibrosis, calcification and cyst formation are related to the development of ligamentum flavum cysts $^{20)}$.

Ligamentum flavum cysts must be differentiated from the synovial or ganglion cysts which are common lesions occurring in the facet joints. Kao et al. and Rhoton et al. ${ }^{15)}$ distinguished these two lesions according to several factors. Synovial cysts arise from the facet joints and remain outside the ligamentum flavum. Characteristically, they have a synovial lining membrane. They are continuous with the joint space and are lined by pseudostratified columnar epithelium, and are filled with clear and xanthochromic fluid. In contrast, ganglion cysts have no synovial lining membrane and do not communicate with the facet joint, and contain gelatinous material. Both are usually found at the L4-5 level ${ }^{38}$. So we think that this is a case of synovial cyst from facet joint.

The differential diagnosis of cystic lesions involving the ligamentum flavum includes granuloma, intraligamentous amyloid deposition, ossification, myxomatous degeneration and hematoma, perineural cyst, intraspinal dermoid cyst, neurofibroma, hydatid cysts or cysticercosis ${ }^{5,15}$.

Radiological differentiation of ligament flavum cysts is difficult. Plain X-rays mostly show only degenerative changes. Myelogram showed the intraspinal extradural masses compressing the nerve root sleeve ${ }^{4)}$. Because the radiologic features are nonspecific, differentiation from other intraspinal cysts is very difficult.

Recently MRI has been widely used for diagnosis of juxtafacet cyst, but no specific features have been reported. Generally, the cysts have a variable signal on T1-wighted and a hyperintense $\mathrm{T} 2$-weighted images ${ }^{26}$. In our patient, the ligamentum flavum cyst was isodense with air on CT, isointense in T1 and T2-weighted MRI, and there was no communication with the spinal facet joint. Ligament flavum cyst often occur with intraluminal hemorrhage, and sometimes air or gas forming ligamentum flavum cysts have been reported.

Conservative therapy has not shown successful results. Percutaneous steroid injection of the facet and juxta-facet cysts also has effect on short term ${ }^{7}$. Percutaneous aspiration of cyst has not been effective. Surgical excision is the treatment of choice. The goal of surgery is spinal decompression and resection of the cyst and the affected ligamentum flavum. 
If complete excision of the cyst is performed, recurrence is unlikely $^{2}$. The presence of adhesions to the dura is known to be the main factor in incomplete resection and recurrence ${ }^{18)}$. The neurological outcome after surgical treatment is good, including the improvement of pain ${ }^{8}$.

\section{CONCLUSION}

Ligamentum flavum cyst is a rare cause of spinal compression and radiculopathy. Because of its rarity and the nonspecific clinical and radiologic findings, the preoperative diagnosis is not easy. It can be distinguished from other juxtafacet cysts by several findings. We report the ligamentum flavum cyst on lumbar spine which was successfully treated by surgical excision and literature review.

\section{REFERENCES}

1. Azzam CJ: Midline lumbar ganglion/synovial cyst mimicking an epidural tumor: case report and review of pathogenesis. Neurosurgery 23:232, 1988

2. Baba H, Furusawa N, Maezawa Y, Uchida K, Kokubo Y, Imura $\mathrm{S}$, et al: Ganglion cyst of the posterior longitudinal ligament causing lumbar radiculopathy: case report. Spinal Cord 35:632, 1997

3. Banning CS, Thorell WE, Leibrock LG: Patient outcome after resection of lumbar juxtafacet cysts. Spine 26:969, 2001

4. Baum JA, Hanley JR EN: Intraspinal synovial cyst simulating spinal stenosis: A case report. Spine 11:487, 1986

5. Bilbao J, Horsey W, Gonsalves C, Chalvardjian A: Compression of the cauda equina due to a necrobiotic granuloma of ligamentum flavum. Can J Neurol Sci 2:135, 1975

6. Brotis AG, Kapsalaki EZ, Papadopoulos EK, Fountas KN: A cervical ligamentum flavum cyst in an 82-year-old woman presenting with spinal cord compression: a case report and review of the literature. J Med Case Rep 6:1-6, 2012

7. Bureau NJ, Kaplan PA, Dussault RG: Lumbar Facet Joint Synovial Cyst: Percutaneous Treatment with Steroid Injections and Distention-Clinical and Imaging Follow-up in 12 Patients. Radiology 221:179-185, 2001

8. Chan L, Lui C, Cheng M, Lin J: Ganglion cyst in the ligamentum flavum of the cervicothoracic junction. J Formos Med Assoc 95:490-492, 1996

9. Chimento GF, Ricciardi JE, Whitecloud 3rd T: Intraspinal extradural ganglion cyst. J Spinal Disord 8:82, 1995
10. Ehni G: Spondylotic cauda equina radiculopathy. Tex Med 61: 746, 1965

11. Freidberg SR, Fellows T, Thomas CB, Mancall AC: Experience with symptomatic spinal epidural cysts. Neurosurgery 34:989, 1994

12. Gazzeri R, Galarza M, Gorgoglione L, Bisceglia M, D'Angelo V: Cervical cyst of the ligamentum flavum and C7-T1 subluxation: case report. Eur Spine J 14:807-809, 2005

13. Hatem O, Bedou G, Négre C, Bertrand JL, Camo J: Intraspinal cervical degenerative cyst: report of three cases. J Neurosurg Spine 95:139-142, 2001

14. Hsu KY, Zucherman JF, Shea WJ, Jeffrey RA: Lumbar intraspinal synovial and ganglion cysts (facet cysts). Ten-year experience in evaluation and treatment. Spine 20:80, 1995

15. Kao CC, Winkler SS, Turner J: Synovial cyst of spinal facet. J Neurosurgery 41:372-376, 1974

16. Kruse JJ, Awasthi D, Harris M, Waguespack A: Case Report. Ossification of the Ligamentum Flavum as a Cause of Myelopathy in North America: Report of Three Cases. J Spinal Disord 13:22, 2000

17. Lunardi P, Acqui M, Ricci G, Agrillo A, Ferrante L: Cervical synovial cysts: case report and review of the literature. Eur Spine J 8:232-237, 1999

18. Lyons MK, Atkinson JLD, Wharen RE, Deen HG, Zimmerman RS, Lemens SM: Surgical evaluation and management of lumbar synovial cysts: the Mayo Clinic experience. J Neurosurg Spine 93:53-57, 2000

20. Moiel RH, Ehni G, Anderson MS: Nodule of the ligamentum flavum as a cause of nerve root compression. Case report. J Neurosurgery 27:456, 1967

32. Ramani P, Perry R, Tomlinson B: Role of ligamentum flavum in the symptomatology of prolapsed lumbar intervertebral discs. J Neurol Neurosurg Psychiatry 38:550-557, 1975

21. Rhoton A, Kao C, Uihlein A: Extradural ganglion cyst. Handbook of Clinical Neurology North-Holland Pub Co, Amsterdam: North Holland: 605-609, 1976

22. Savitz MH, Sachdev VP: Cyst of the ligamentum flavum: report of six cases. Neurosurgery 30:461, 1992

23. Joung SH, Park HS, Rhee DY, Song JS, Heo W: Cyst of the Ligamentum flavum. Korean J Spine 4:84-87, 2007

24. Takano Y, Homma T, Okumura H, Takahashi HE: Ganglion cyst occurring in the ligamentum flavum of the cervical spine: a case report. Spine 17:1531-1533, 1992

25. Yoshii S, Ikeda K, Murakami H: Myxomatous degeneration of the ligamentum flavum of the lumbar spine. Spinal Cord 39: 488-491, 2001

26. Yuceer N: Hematoma of the ligamentum flavum in the lumbar spine: case report. Surg Neurol 53:598-600, 2000 